\title{
MODOS CONTEMPORÂNEOS DE CONSTITUIÇÃO DA DOCÊNCIA NA EDUCAÇÃO BÁSICA NO BRASIL: UM ESTUDO EM TRÊS TEMPOS \\ (1960-2000)
}

\author{
Roberto Rafael Dias da SILVA ${ }^{1}$ \\ Alessandra de Abreu CORRÊA ${ }^{2}$
}

RESUMO: O presente artigo busca examinar os modos contemporâneos de constituição da docência. A partir de uma análise documental de três livros de importante impacto na literatura educacional brasileira, todos oriundos de pesquisa empírica de seus autores, propõe-se um breve exercício analítico, procurando mapear as concepções de pesquisa sobre a docência na Educação Básica que predominaram (e em muito ainda predominam) no Brasil, tomando como ponto de partida para este artigo o ano de 1960. Assim sendo, seu compromisso está em estabelecer um diagnóstico crítico das principais tendências analíticas que orientaram a produção brasileira nos últimos cinquenta anos. De forma derivada aos estudos examinados, fez-se possível indicar três tendências predominantes: a) crítica das condições de burocratização e regulação da docência no Brasil, servindo-se de abordagens de caráter sociológico; b) a competência técnica como elemento indispensável na produção de uma escola democrática, da mesma forma que os saberes escolares são ferramentas fundamentais para esse processo; c) a qualidade das práticas docentes devem ser acompanhadas de um direcionamento ético-político.

PALAVRAS-CHAVE: Docência. Educação básica. Análise documental. Brasil.

O mínimo que se exige de um educador é que seja capaz de sentir os desafios do tempo presente, de pensar a sua ação nas continuidades e mudanças do trabalho pedagógico, de participar criticamente na construção de uma escola mais atenta às realidades dos diversos grupos sociais (NÓVOA, 1999).

Estudar a docência tem se constituído como um dos temas mais importantes dos estudos contemporâneos em educação. Para além de delinear métodos ou soluções pedagógicas diferenciadas, a literatura contemporânea tem nos desafiado a examinar os modos de constituição desta atividade profissional. Tornou-se consenso refletir sobre as formas de exercício da profissão, as modalidades de formação inicial e continuada ou mesmo os saberes implicados nas práticas profissionais (TARDIF, 2010; SANTOMÉ; 2006; GAUTHIER, 2006). Enfim, não precisamos de um esforço muito significativo para assinalar que, do ponto de vista acadêmico, estamos nas últimas décadas redescobrindo

\footnotetext{
${ }^{1}$ UFFS - Universidade Federal da Fronteira Sul; Doutor em Educação. UNISINOS - Universidade do Vale do Rio dos Sinos. Erechim - RS - Brasil. 99700-000 - robertosilva@uffs.edu.br.

${ }^{2}$ URI - Universidade Regional Integrada do Alto Uruguai e das Missões; Mestre em Educação em Ciências e Matemática. PUCRS - Pontifícia Universidade Católica do Rio Grande do Sul. Erechim - RS - Brasil. 99700-000 - aleacorrea@yahoo.com.br.
} 
ou reinventando os estudos sobre a docência (NÓVOA, 2009; GATTI; BARRETO, 2009; PIMENTA, 1996).

Entretanto, para que estes estudos consigam avançar e possamos consolidar uma pauta investigativa sobre a docência no Brasil parece-nos que ainda precisamos nos reencontrar com um conjunto de documentos históricos que nos auxiliem a caminhar nessa direção. O entendimento da docência como uma prática permite-nos situá-la em suas dimensões sociais e históricas para que explicitemos, com algum grau de rigor e profundidade, algumas tendências analíticas dos estudos em docência em nosso País. Ainda que estejamos propondo um movimento em uma área com uma acentuada pulverização discursiva, nosso interesse investigativo está circunscrito a uma compreensão dos estudos em docência no Brasil a partir de 1960. A partir de uma análise documental de três livros de importante impacto na literatura educacional brasileira, proporemos um breve exercício analítico, procurando mapear alguns rastros das concepções de pesquisa sobre a docência na Educação Básica que predominaram (e em muito ainda predominam) no Brasil, tomando como ponto de partida para este artigo o ano de 1960.

Assim sendo, nosso compromisso está em estabelecer um diagnóstico crítico de três das principais tendências analíticas que orientaram a produção brasileira na segunda metade do último século. Tal como anunciamos desde o título escolhido para este texto, intencionamos produzir um estudo em três tempos. Para iniciarmos esse percurso escolhemos tratar da produção desenvolvida nos anos 1960 a partir de uma pesquisa produzida pelo sociólogo da educação Luiz Pereira. A escola numa área metropolitana é o texto que analisaremos na primeira seção deste texto. $O$ segundo texto que examinaremos trata-se de Magistério de $1^{o}$ grau: da competência técnica ao compromisso político, de Guiomar Namo de Mello, produzido no início da década de 1980. Por fim, ao tratarmos dos anos 2000, fomos conduzidos a estudar um dos instigantes livros de Terezinha Rios, Compreender e ensinar: por uma docência da melhor qualidade.

Cabe reiterar que nossa intenção não esteve em produzir estudos comparativos, nem mesmo esgotar analiticamente as temáticas desenvolvidas em cada um dos livros. Escolhemos três exemplares da intensa produção acadêmica no País sobre o tema, documentos significativos de três modalidades distintas (e qualificadas) de produzir estudos educacionais. Demarcamos ainda o compromisso em, ao delinear tendências investigativas, ao final do estudo, produzir um esboço de sistematização que nos permita 
interrogar o presente e o futuro com maior rigorosidade. Uma vez que, como assinala a epígrafe que escolhemos para este texto, tomamos a história como uma ferramenta que nos permita sentir os desafios do presente.

\section{Paternalismo e burocratização da profissão docente: os estudos de Luiz Pereira}

A partir dos resultados de um estudo empírico desenvolvido no final da década de 1950, o sociólogo Luiz Pereira, publicou o livro "A escola numa área metropolitana: crise e racionalização de uma empresa pública de serviços", no ano de 1967. A pesquisa da qual o livro deriva trata-se de um estudo de caso sobre as relações entre a escola e a comunidade local, considerando-se o contexto de uma área urbana do município de Santo André (São Paulo - Brasil) (PEREIRA, 1967). Do ponto de vista metodológico, o estudo considerou um conjunto amplo e diversificado de materiais empíricos: observações sistemáticas do pesquisador, os arquivos e registros diversos da escola estudada, observação da vida social da comunidade e do comportamento dos professores, legislação escolar e obras pedagógicas referentes à escola primária e produções textuais dos alunos da $4^{\mathrm{a}}$ série.

O autor parte do pressuposto de que o movimento pedagógico renovador, em desenvolvimento no País naquele período, não possuía elementos suficientes para realizar um planejamento qualificado e adequado para a educação nacional. Ao inspirar-se no trabalho dos sociólogos brasileiros, marcadamente a sociologia de Florestan Fernandes, e nas obras clássicas de Max Weber, com seu estudo Pereira pretendia “[...] estar propiciando mais uns elementos para o conhecimento mais amplo e profundo da realidade escolar brasileira". (PEREIRA, 1967, p.14).

A escola de Água Redonda, nome fictício apresentado pelo pesquisador, possuía mil seiscentos e oitenta e quatro estudantes e localizava-se em uma área de recente e crescente aumento populacional. Em pouco tempo as oito salas de aula existentes tornaram-se insuficientes e a instituição pública de ensino passou a funcionar em três turnos, reduzindo o período letivo diário de quatro para três horas-aula. Mais que as mudanças estruturais que aconteciam recorrentemente na escola, a análise de Luiz Pereira apontará as mudanças na dinâmica social da instituição, permitindo com que o pesquisador nomeie esse cenário como "escola primária brasileira em mudança". (PEREIRA, 1967). 
Para delinear esse conceito, o autor posiciona-o na interface entre dois processos distintos e complementares. Por um lado, notava-se que a escola apresentava traços de um acentuado processo de burocratização, no sentido weberiano do termo. Os professores, em sua relação com o trabalho, com os estudantes e com a comunidade local, tendiam a demonstrar uma forte institucionalização de sua profissionalidade e de sua vida institucional. Por outro lado, em concomitância ao processo de burocratização, aponta-se a condição social brasileira em um amplo "avanço da etapa urbano-industrial capitalista". No município de Santo André, por conta do amplo processo de industrialização em curso, era possível visualizar "[...] a passagem de uma ordem global pré-capitalista para outra capitalista”. (PEREIRA, 1967).

Considerando o cenário explicitado no parágrafo acima, a pesquisa de Pereira buscará descrever os diferentes elementos constituintes daquela realidade educacional. Para fins da análise aqui proposta, a partir de agora nos centraremos na descrição produzida sobre a atuação profissional dos professores. Ao estudar o Regimento Escolar daquela instituição, o pesquisador assinala que as atribuições dos professores estavam organizadas em três setores: "[...] o das atividades relativas à sua classe ou turma de alunos, o das suas atividades extra-classe, e o das suas relações com os colegas e demais funcionários da escola". (PEREIRA, 1967, p.74).

O primeiro setor de atividades, aquele que demandava maior tempo e dedicação dos professores, caracterizava-se por três conjuntos de atividades: “[...] as docentes, as de controle dos alunos e as de 'escrituração"'. (PEREIRA, 1967). O autor destaca que no Regimento da instituição, as atividades de ensino, são descritas tanto em termos dos conteúdos a serem ensinados, quanto das técnicas de ensino a serem implementadas. Considerando as condições históricas das instituições analisadas, o autor notava que, ainda que estivessem assentadas em um cânone tradicional das práticas escolares, em sua documentação procuravam, de diferentes modos, articular-se com os princípios das pedagogias novas, de inspiração escolanovista, bastante em evidência no Brasil no final da primeira metade do último século.

Segundo esse estatuto, "o ensino terá por base essencial a observação e a experiência pessoal do aluno e dará a este largas oportunidades para o trabalho em comum, a atividade manual, os jogos educativos e as excursões escolares" (art. 11), devendo o professor "ministrar suas aulas de maneira objetiva, motivando-as de forma a despertar o interesse dos educandos e pugnar sempre por uma renovação de procedimento e de conduta educativa" (art. 26). Além desses procedimentos de caráter geral, outros de caráter geral, outros mais particularizados se 
depreendem da obrigatoriedade de cada professor organizar o horário semanal de suas aulas (art. 13) e de redigir o semanário ou diário de lições que deverão constituir-se em planos de trabalho" (arts. 14 e 26). (PEREIRA, 1967, p.74-75).

Para além dessas atividades, Pereira (1967) ainda descreve como papel do professor, na escola analisada, combater às más leituras que poderiam deturpar o caráter e incentivar nos estudantes hábitos estéticos e asseio pessoal. Nota-se, então, que o lugar de professor nas escolas da década de 1950, assumia uma função civilizatória bastante significativa (VIDAL, 2010; GONDRA, 2010). Em decorrência disso, o sociólogo apresenta o segundo conjunto de atividades docentes, vinculadas ao controle dos estudantes. Ao explicar esse conceito - controle dos estudantes -, Pereira explica que "[...] abrange a manutenção da disciplina dos alunos, a verificação do seu rendimento ou aprendizado, e a fiscalização do seu comparecimento e permanência na escola". (PEREIRA, 1967, p.75).

As atividades de controle descritas por Pereira (1967) abrangiam, fundamentalmente, a perspectiva de manter as salas de aula organizadas, tanto que se refere ao rendimento, quanto à disciplina dos estudantes. $\mathrm{O}$ destaque feito do Regimento Escolar analisado, que busca garantir sua conformidade aos princípios da pedagogia nova, está na obrigatoriedade no uso de "métodos suasórios" para essas atividades de controle. Em outras palavras, a documentação escolar exige que os docentes façam uso da persuasão no tratamento dos estudantes, sendo vedado o uso de castigos corporais, punições morais ou linguagem inconveniente. Sob esse cenário, caberia ao professor, em situações pertinentes, propor ao diretor da instituição que faça uso das penalidades apropriadas, ou ainda atribuir ao estudante uma nota mensal de comportamento (grifo nosso). Tal nota, segundo o documento examinado “[...] traduzirá o seu julgamento sobre a urbanidade e o espírito de colaboração do aluno com o mestre e os colegas, revelado durante a realização das tarefas escolares”. (PEREIRA, 1967, p.75). Cabe reiterar que a busca pela urbanidade também é posicionada na conduta dos próprios professores, em sua obrigatoriedade em participar de reuniões convocadas, solenidades, campanhas educativas, organização de festas, dentre outras atividades.

Em consonância a essa última afirmativa, cabe destacar o terceiro conjunto de atividades docentes, descritas por Pereira na escola de Água Redonda, que está nas relações com os colegas e funcionários da instituição escolar. O referido Regimento aponta como norma fundamental a necessidade de os professores tratarem com “delicadeza e urbanidade" os demais funcionários da escola, garantindo que as relações 
sejam de ordem institucional, evitando personalizá-las, no sentido de solicitar favores pessoais aos funcionários. $\mathrm{O}$ texto indica ainda a obrigatoriedade de "[...] manter com os colegas, e demais funcionários, espírito de colaboração e camaradagem indispensáveis à unidade do trabalho educativo da escola". (PEREIRA, 1967, p.77). Antes de avançarmos importa destacar que, na medida em que Pereira desenvolveu uma pesquisa de campo bastante aprofundada na escola de Água Redonda, o sociólogo brasileiro ressalva que há inúmeras inconsistências internas nesse Regimento, sobretudo no que tange às ambivalências entre os modelos tradicionais de ensino e os princípios pedagógicos escolanovistas.

Para além disso, o estudo de Pereira (1967) encaminha que, mesmo sendo um instrumento fundamental de regramento da conduta dos sujeitos escolares, o Regimento não conseguia delinear uma concepção de docência apropriada para aquele tempo, visto que os professores não se deixavam definir burocraticamente. A ambivalência entre o modelo tradicional de escola e os desdobramentos da configuração emergente de escola, visto que, em uma terminologia weberiana, o sociólogo percebe a constituição de uma "personalidade-status ideal" de professor primário vigente entre os docentes de Água Redonda. O fragmento a seguir, ainda que extenso, evidencia as constatações investigativas de Pereira quanto a este aspecto.

\footnotetext{
Essa personalidade-status ideal de professor é congruente com a representação patrimonialista da escola primária pública: como algo "pertencente" ao seu pessoal docente-administrativo, que presta uma espécie de favor aos alunos e suas famílias, "ajudando-os na vida" graças ao ensino das técnicas elementares da cultura - leitura, escrita e cálculo. O "bom" professor primário dedica-se grandemente aos alunos, sentindo-se tanto um "dono" do seu cargo e das crianças de sua classe. Em visto disso, não admite interferência dos pais descontentes: "aqui mando eu no seu filho" é frase compatível com tal concepção. Da mesma forma, não aprecia o controle do diretor sobre as atividades que dizem respeito à sua classe. Resolve tudo sozinho, só recorrendo ao diretor em casos extremos. (PEREIRA, 1967, p.78, grifos nosso).
}

Assim sendo, o professor constituído na pesquisa de Pereira (1967) reconhece as tarefas concernentes a sua sala de aula, ao ensino, ao controle e à escrituração de seu trabalho, mas evita relacionar-se com os problemas da escola, em particular, e da comunidade, em geral. Sob essa lógica, não apresenta as referidas "relações de camaradagem" com os demais trabalhadores da escola e com a comunidade (visto que segundo a referida investigação, os professores ainda fazem uso de castigos físicos e esperam pequenos favores dos pais e funcionários). $\mathrm{O}$ "bom" professor, na personalidade- 
status descrita pelo sociólogo, revela-se pela ordem e silêncio que seus alunos manifestam e pelas notas altas que recebem nos trabalhos escolares. Uma alta porcentagem de aprovação é o objetivo buscado pelos professores, visto que isto lhe garantia a efetivação no cargo ou ainda, para os efetivados, a melhor pontuação nas tabelas de promoção do plano de carreira.

Com esse objetivo, então, “[...] o ensino não precisa necessariamente adotar técnicas pedagógicas recomendadas nas escolas normais, pois o importante é a aprovação do aluno". (PEREIRA, 1967, p.79). Coexistente a essa configuração, Pereira ainda diagnostica uma vinculação da profissão a traços reconhecidos como femininos: “[...] carinho, paciência, compreensão, etc. para com as crianças, ligadas ao que se costuma chamar de instinto maternal'. (PEREIRA, 1967, p.79, grifo nosso). Entretanto, conforme o autor, esse estereótipo está em amplo deslocamento, em nome de uma docência burocratizada.

\begin{abstract}
Trata-se da concepção paternalista do magistério primário como atividade artesanal-missionária, substituída em grande escala por concepções burocráticas acerca da profissão, que levam os professores a encará-la em termos instrumentais, avaliando-a de acordo com as compensações obtidas através do trabalho - justamente as compensações burocráticas inerentes ao cargo. (PEREIRA, 1967, p.82).
\end{abstract}

A análise de Pereira (1967) sobre a escola brasileira do final da década de 1950, mostra-nos, dentre outros aspectos, o deslocamento entre uma concepção paternalista do magistério e uma concepção burocratizada desse agrupamento profissional. A abordagem do sociólogo brasileiro não supõe que os modelos apresentem temporalidades diferentes; pelo contrário, o cenário examinado expõe a coexistência dos modelos. A ênfase que procuramos visibilizar é que questões contemporâneas como as queixas pelo desinteresse dos alunos, pelos baixos salários, pela dificuldade de relacionamento com a comunidade escolar ou pelo modelo de cultura escolar individualista podem ser visibilizados no cenário brasileiro durante o período examinado. $\mathrm{O}$ reconhecimento profissional dos professores no Brasil, desde a sociologia de Luiz Pereira, fabricou-se na ambivalência entre o paternalismo e a burocratização. Herdamos deste pensamento a possibilidade de produção de uma postura crítica sobre a escola brasileira do século XX, uma postura investigativa que questiona os modos de produção do trabalho docente, sua relevância social e suas repercussões nos cotidianos das comunidades. Considerando o movimento de busca de uma sociedade e de uma escola democráticas, a seguir daremos alguns passos 
na direção de pensarmos o lugar da competência técnica no trabalho do professor, questão central dos estudos pedagógicos do final dos anos de 1970 e na transição democrática do início dos anos de 1980.

\section{A competência técnica em uma escola democrática}

Transcorria-se o início da década de 1980 e os estudos educacionais no Brasil começavam um intenso processo de pluralização teórica (SAVIANI, 2008; SAVIANI, 2011; LOPES; FARIA FILHO; VEIGA, 2010). Desde abordagens tecnicistas até diferentes perspectivas progressivistas, os debates procuravam produzir estudos analíticos sobre a qualidade na escola pública. Entretanto, tal debate era delineado; por um lado, pela emergente teorização de Pierre Bourdieu sobre a reprodução e, por outro lado, pela emergência dos estudos que consideravam a centralidade dos saberes dos populares (FREIRE, 1987). Concomitantemente, o Brasil experienciava suas lutas políticas pela reabertura democrática e o teor dos estudos pedagógicos assinalavam forte influência nesse cenário. Acreditava-se na escola pública como instância determinante na reconstituição de uma sociedade democrática.

Uma das correntes teóricas emergentes deste período ficou conhecida como histórico-crítica e teve como um de seus principais expoentes o professor Dermeval Saviani. Inúmeros dos estudos por ele conduzidos ou orientados naquele período, privilegiavam, na composição de uma escola democrática, retomar a centralidade dos saberes historicamente produzidos para as práticas pedagógicas na escola pública. Diferentemente de outras correntes progressivistas que se consolidavam naquele período, a abordagem histórico-crítica entendia que a escola democrática era aquela que oferecia aos sujeitos escolares tudo aquilo que, ao longo do tempo, a humanidade produziu intelectualmente (SAVIANI, 2011).

Obviamente que a referida abordagem analítica, ainda que derivada dos estudos marxistas, não produzia teorizações convergentes ou consensuais a todo tempo. Um dos debates que, no interior dessa corrente, gerou inúmeras controvérsias referia-se ao debate sobre as relações entre competência técnica e compromisso político na docência na educação pública. Os debates entre Paolo Nosella e Guiomar Namo de Mello, ambos orientandos de Saviani, são exemplares desse debate. Entretanto, para além disso, segundo Saviani (2011), o que havia de intersecção entre essas abordagens estava na perspectiva de trilharem “[...] um caminho sem retorno no processo de reapropriação, por 
parte das camadas trabalhadoras, do conhecimento elaborado e historicamente acumulado". (SAVIANI, 2011, p.55).

Para os fins de nosso estudo, de modo a acompanhar as políticas de constituição da docência no Brasil, neste momento, atribuiremos ênfase ao estudo de Mello (1984) que, em nossa leitura, trata-se de uma pesquisa que consegue, além de sistematizar as principais contribuições da abordagem histórico-crítica no que tange à docência, resguarda a dimensão técnica do fazer docente e assinala o compromisso da escola com o saber escolar, delineando novas perspectivas acerca da constituição da docência em nosso País. O ponto de partida da referida pesquisa está no papel político inerente às instituições públicas de ensino o que, direta ou indiretamente, conduz a um pensamento tanto sobre as seletividades que perfazem este processo, quanto às mediações intra-escolares nele mobilizadas.

Nessa direção, a autora considera, inicialmente, a existência de mecanismos de seletividade nas condições escolares, questões essas " [...] que contribuem para o fracasso escolar das crianças de origem social e econômica desfavorecida, ainda que grande parte desse fracasso se deva sem dúvida à pobreza material de que essas crianças são vítimas". (MELLO, 1984, p.15). Ainda que considere esse aspecto, de forma central, o estudo de Mello não fica circunscrito a isso, propõe-se a delinear, dialeticamente, outras condições escolares marcadas pela qualidade e pelas oportunidades de apropriação dos conteúdos escolares a todos os estudantes.

\begin{abstract}
As condições escolares podem ser desde já de qualidade e teor tal que não se limitem a apenas confirmar a previsão de fracasso inscrita na origem econômica da criança. Ainda que não possam alterar esta origem, elas podem ser menos selecionadoras e garantir às crianças pobres oportunidades de apropriação dos conteúdos escolares básicos que são necessários, ainda que longe estejam de ser suficientes, às suas estratégias de sobrevivência, as quais podem incluir - dependendo de outras instâncias sociais - inclusive a negação da opressão econômica. Para isso, a forma de operar da escola terá que ser tecnicamente adequada às características dessas crianças. Garantindo melhores condições de aprendizagem a elas, realiza-se seu sentido político. (MELLO, 1984, p.15).
\end{abstract}

Considerando as dimensões acima delineadas, a pesquisadora esboça a hipótese que será explorada em sua investigação, a saber: que o sentido político da prática profissional do professor também efetiva-se pela sua competência técnica. Ao compor sua estratégia argumentativa, Mello (1984) procura distanciar-se dos estudos sobre a reprodução, inspirados em Bordieu e Passeron (1975), especialmente da noção de 
violência simbólica. Conforme o referido conceito, a escola pode exercer um tipo de dominação sobre os diferentes argumentos sociais para além da força física, utilizando determinados sistemas simbólicos. Para operar esses sistemas, a instituição escolar lança mão de determinados saberes, indicados na teorização como arbitrários, que são impostos "[...] a indivíduos de outros grupos que não aqueles no interior do qual ou para o qual ele foi produzido". (MELLO, 1984, p.17).

O tipo de crítica produzido pela autora sugere que a escola não apenas reproduz determinadas condições sociais, mas produz reações a essas estruturas. Do ponto de vista do conhecimento escolar, indica-se que este não apenas posiciona-se como um arbitrário cultural.

[...] O que acontece na escola, do ponto de vista do aluno, é aprendizagem e socialização, processos que podem ser abstraídos em termos de padrões ou tendências coletivas, mas que concretamente se efetuam em cada indivíduo singular. Neste sentido, ao aceitar a determinação que a economia ou a cultura exercem sobre a escola, ao reconhecer que esta reúne, organiza, manipula e procura transmitir um corpo de conhecimentos, condutas e hábitos, historicamente produzidos no seio de uma sociedade determinada, estamos dando conta de uma parte do papel que ela desempenha, mas não de tudo. (MELLO, 1984, p.27).

Para além da transmissão de conteúdos arbitrariamente selecionados, Mello (1984) encaminha a perspectiva de entendimento da instituição escolar como mediadora entre as questões sociais e as individualidades. Na leitura proposta, reconhece-se "[...] que a natureza, a qualidade e o resultado da experiência escolar devem fazer alguma diferença sobre o modo como cada indivíduo vai realizar seu destino social". (MELLO, 1984, p.27). Em outras palavras, a escola pode operar na melhoria das condições sociais, na medida em que o saber ensinado permite uma compreensão do mundo, inclusive das relações de dominação a que os indivíduos são expostos.

Assim sendo, o ensino de conceitos de comunicação e cálculo, conhecimentos físicos e sociais, exercem um papel fundamental para uma "boa escolarização". Tal configuração dos processos escolares, ainda segundo a pesquisadora, é bastante coerente com os estudos marxistas. A partir de uma releitura de textos de Marx e Gramsci, bastante recorrente na pedagogia histórico-crítica que a subsidia, Mello (1984, p.33) descreve a escola como "[...] transmissora de conhecimentos úteis também aos dominados, promotora de oportunidades de melhoria de vida. É esse seu sentido propriamente político e como tal contraditório". 
Aqui explicitam-se os sentidos da docência e da transmissão escolar na composição analítica proposta pela pesquisa. Os sentidos políticos da educação escolarizada também materializam-se "[...] na exigência da competência técnica da escola para realizar bem aquilo a que se propõe: ensinar a todos os que a ela têm acesso e estender-se aos até agora excluídos". (MELLO, 1984, p.34). Sob essa gramática, professor crítico também pode ser o que bem ensina.

A competência técnica, o saber fazer bem, é a passagem, a mediação, pela qual se realiza um dos sentidos políticos em si da educação escolar. É com ela, a competência, e com ele, o sentido político em si, que pretendo trabalhar na interpretação dos dados empíricos acerca das representações dos professores, tomando-os como uma das condições escolares. (MELLO, 1984, p.34).

Os estudos de Mello, referenciados na pedagogia histórico-crítica, contribuíram para uma ressignificação dos modos de constituição da docência, uma vez que resguardam a dimensão técnica do fazer docente e assinalam o compromisso da escola com o conhecimento produzido historicamente. Mesmo que a condição docente já estivesse burocratizada no Brasil, como supunha Luiz Pereira no final dos 1950, sobretudo após as políticas de escolarização implementadas desde os governos dos militares, a pesquisa de Mello desafia-nos na direção de uma docência mais democrática. Diferentemente das demais perspectivas progressivistas em voga em nosso País nos anos de 1980, a abordagem produzida pela autora permite a compreensão de que a docência democrática precisa estar acompanhada de competência técnica.

\section{Qualidade, compromisso social e cidadania: outras agendas}

No contexto dos anos 2000 um dos trabalhos que obteve significativa circulação nas pesquisas em educação no Brasil, foi o livro "Compreender a ensinar: por uma docência da melhor qualidade", de Rios (2006). O texto, derivado de sua tese de doutorado, busca inscrever-se no campo da Didática, mas procura permanentemente interfaces com a Filosofia da Educação. Segundo a pesquisadora anuncia na introdução de seu livro, o núcleo de suas investigações encontra-se junto "[...] a formação e a prática dos educadores e educadoras e a necessidade de pensá-las fazendo recurso a uma perspectiva crítica”. (RIOS, 2006, p.19). Nesse sentido, Rios (2006) privilegia uma composição conceitual que articula as noções de qualidade, competência e cidadania, na 
medida em que reconhece a perspectiva de que uma prática docente realizada com competência, de boa qualidade, conduz a uma formação cidadã.

Suas inquietações investigativas derivaram-se de sua prática profissional enquanto professora de Filosofia. Diferentes demandas que perpassam a vida social contemporânea, como a fragmentação das relações sociais, a globalização ou razão instrumental, mobilizaram as reflexões acadêmicas da pesquisadora, de forma que problematizasse aspectos de sua prática. Dessas demandas, Rios (2006) compromete-se em estabelecer um entendimento do fenômeno do ensino como uma "[...] totalidade concreta"; isto é, desafiava-se a pensar as práticas docentes em suas relações com outras questões sociais, fazendo da Didática também um campo de crítica.

Tomando como ponto de partida a consideração da didática como um campo crítico-reflexivo, a pesquisadora defenderá uma abordagem analítica que entende que “[...] o ensino competente é um ensino de boa qualidade". (RIOS, 2006). Ao tratar da qualidade, Rios (2006) ingressa em um campo de problematização que, de certa forma, atravessa a história recente de nossa educação. A efetivação de uma educação de qualidade tem presença constante nos discursos políticos das últimas décadas, ao mesmo em que se apresentou como um campo de reflexão educacional nesse período. Entretanto, sua abordagem reconhece uma dimensão histórica para o conceito de qualidade, tanto que a autora o nomeia como "qualidade sócio-cultural", diferenciando-se da noção de qualidade total, bastante em voga na educação brasileira dos anos 1990.

Falar de qualidade total é, pois, fazer referência a algo que se cristaliza, fica preso num modelo. $\mathrm{O}$ que se deseja para a sociedade não é uma educação de qualidade total, mas uma educação de melhor qualidade, que se coloca sempre à frente, como algo a ser construído e buscado pelos sujeitos que a constroem. (RIOS, 2006, p.74).

Para movimentar-se pela questão, o estudo aqui examinado encaminha uma vinculação ao conceito de competência. Para a autora, servindo-se dos estudos de Philippe Perrenoud, as competências tendem a mobilizar e integrar determinados saberes para o enfrentamento de problemas a serem resolvidos. Nessa leitura, nota-se que "[...] a competência implica, também, uma capacidade de atualização dos saberes”. (RIOS, 2006, p.77). Acerca desse aspecto, Rios (2006) procura distanciar-se de uma leitura bastante difundida naquele contexto que é a vinculação entre as competências e as demandas do mercado. Isto se faz possível pela operacionalização de um entendimento que trata como indissociáveis as dimensões técnica e política do fazer educativo. 
Sua leitura direciona uma referência ao bem comum como eixo de articulação entre os aspectos da técnica e da política, postulando uma compreensão da competência como “[...] um conjunto de saberes e fazeres de boa qualidade”. (RIOS, 2006). A prática educativa competente, em consonância com essa leitura, remete-nos a conclusão de que as noções de competência e qualidade podem ser relacionadas, na medida em que visam ressignificar as ações pedagógicas. Os sentidos de qualidade mobilizados não se ancoram em padrões estáveis ou pré-definidos, mas revestem-se de um "caráter cultural e histórico". (RIOS, 2006). A seguir exploraremos as dimensões da competência elaboradas analiticamente pela pesquisadora.

Rios (2006) sugere que toda ação docente é constituída de quatro dimensões fundamentais, a saber: técnica, estética, política e moral. Em torno da primeira dimensão, a pesquisadora destaca sua posição enquanto "suporte da competência", uma vez que, toda ação competente, supõe um domínio de ferramentas teóricas para que o profissional possa agir de forma consciente e autônoma. Outra dimensão referida é questão da estética, reconhecida como uma sensibilidade para a compreensão das dimensões humanas da ação docente. As duas primeiras dimensões, em sua abordagem, estão vinculadas permanentemente, uma vez que "[...] a docência competente mescla técnica e sensibilidade orientadas por determinados princípios, que vamos encontrar num espaço ético-político”. (RIOS, 2006, p.99-100).

Sobre as dimensões ética e política, a pesquisadora indica sua relevância a partir de suas possíveis relações a boa qualidade, são exercitadas “[...] na direção não apenas do bem, entendido com múltiplas significações, como se verifica na moralidade, mas do bem comum". (RIOS, 2006, p.106). A dimensão política vincula-se a construção participativa de uma sociedade, enquanto que a dimensão ética coloca no horizonte a questão do bem comum. Felicidade é o conceito utilizado pela pesquisadora para articular todas essas dimensões e delinear sua tese para esse texto investigativo.

Se a felicidade é sinônimo de bem comum e se é esta a finalidade da vida dos indivíduos em sociedade, o trabalho de todos deve ser orientado para que se alcance esse objetivo. O que é uma vida feliz senão a possibilidade de viver plenamente o direito de acesso aos bens de toda natureza produzidos pela sociedade e de participação na construção de novos bens e direitos? (RIOS, 2006, p.107).

Em torno desse argumento a pesquisadora explicita sua tese, a saber: "[...] o trabalho docente é um trabalho que faz bem". (RIOS, 2006, p.107). Uma docência de qualidade é aquela que procura fazer bem aos estudantes, para a sociedade e para os 
próprios professores. Para explorar esse entendimento, Rios (2006) buscará em Herbert de Souza uma expressão para evidenciar os objetivos de uma prática docente competente - "felicidadania". Em outras palavras, situar a felicidade enquanto uma experiência de vida coletiva, construída pela participação dos cidadãos.

Na compreensão do conceito de felicidadania encontrar-se-ão as perspectivas que foram aqui mencionadas. Cidadania e felicidade colocam-se como intercomplementares. Ganham sentido num espaço verdadeiramente democrático, em que as ações e as relações sustentamse em princípios éticos: afirmam-se as identidades no diálogo, no respeito mútuo, na justiça e na solidariedade e buscam-se condições de uma vida digna. (RIOS, 2006, p.124).

Considerando a argumentação aqui descrita, pode-se inferir que o estudo de Rios privilegia uma abordagem analítica em que "[...] o trabalho docente só serve para colaborar na construção da felicidadania”. (RIOS, 2006, p.135). Sua abordagem analítica articula e consolida novas agendas investigativas que atribuem centralidade ao compromisso social e a promoção da cidadania dos estudantes. Terezinha Rios, em certo sentido, aproxima-se dos estudos histórico-críticos dos anos 1980, porém, propõe um caminho diferenciado ao revitalizar perspectivas de uma matriz nomeada como libertadora (FREIRE, 1987). Isso fica evidenciado nos sentidos teleológicos fortemente delineados para a ação docente, na medida em que postula que o trabalho docente "só serve" para efetivar uma determinada concepção de cidadania. Ainda assim, seus estudos impulsionaram um conjunto de novas pesquisas no campo da docência.

\section{Considerações finais}

Seja pela crítica dos processos de burocratização da docência e das modalidades de institucionalização das escolas, seja pelos modos de constituição da docência através da competência técnica ou da formação para a cidadania, precisamos reconhecer a centralidade adquirida por estes conceitos nos estudos sobre a docência na Educação Básica no Brasil ao longo das últimas décadas. De forma derivada aos estudos examinados, fez-se possível indicar três tendências predominantes: a) crítica das condições de burocratização e regulação da docência no Brasil, servindo-se de abordagens de caráter sociológico; b) a competência técnica como elemento indispensável na produção de uma escola democrática, da mesma forma que os saberes 
escolares são ferramentas fundamentais; c) a qualidade das práticas docentes acompanhadas de um direcionamento ético-político.

É possível concluir que tais tendências consolidaram-se nos estudos contemporâneos sobre a docência em nosso País: ora denunciando suas estratégias políticas de regulação, ora encaminhando dimensões técnicas que se proponham a instrumentalizar a ação docente, ou ainda delineando saberes e fazeres eticamente orientados para a composição de uma escola libertadora. Em prolongamento a esse estudo preliminar, nossa intenção está em produzir um estudo genealógico dos modos pelos quais a instrução juvenil foi sendo constituída nos limites da Modernidade Pedagógica. Procuraremos examinar os principais estudos instituintes de cada uma dessas modalidades de fazer pesquisa sobre a docência na Educação Básica no Brasil.

\section{WAYS OF CONTEMPORARY COMPOSITION OF TEACHING IN BASIC EDUCATION IN BRAZIL: A STUDY IN THREE TIMES}

(1960-2000)

ABSTRACT: This article seeks to examine the constitution of contemporary modes of teaching. From a desk review of three books important impact on Brazilian educational literature, all from empirical research of the authors proposed that a brief analytical exercise, trying to map the concepts of research on teaching in basic education that predominated (and much still predominate) in Brazil, taking as a starting point for this article the year 1960. Therefore, their commitment is critical in establishing a diagnosis of major trends that guided analytical Brazilian production in the last fifty years. Derivatively the studies examined, it was possible to indicate three predominant trends: a) critical conditions of bureaucratization and regulation of teaching in Brazil, helping himself to sociological approaches b) technical competence as an essential element in the production of a democratic school in the same way that school knowledge are fundamental tools for this process, c) the quality of teaching practices must be accompanied by an ethical-political direction.

KEYWORDS: Teaching. Elementary education. Document analysis. Brazil

\section{REFERÊNCIAS}

BOURDIEU, P.; PASSERON, J. C. A reprodução: elementos para uma teoria do sistema de ensino. Rio de Janeiro: Francisco Alves, 1975.

FREIRE, P. Pedagogia do oprimido. 28. ed. Rio de Janeiro: Paz e Terra, 1987.

GATTI, B. A.; BARRETO, E. Professores do Brasil: impasses e desafios. Brasília: UNESCO, 2009. 
GAUTHIER, C. Por uma teoria da pedagogia: pesquisas contemporâneas sobre o saber docente. 2. ed. Ijuí: Ed. da Unijuí, 2006.

GONDRA, J. Medicina, higiene e educação escolar. In: LOPES, M.; FARIA FILHO, L.; VEIGA, C. (Org.). 500 anos de educação no Brasil. 4. ed. Belo Horizonte: Autêntica, 2010. p.520-550.

LOPES, M.; FARIA FILHO, L.; VEIGA, C. (Org.). 500 anos de educação no Brasil. 4. ed. Belo Horizonte: Autêntica, 2010.

484 NÓVOA, A. Apresentação. In: CAMBI, F. História da pedagogia. São Paulo: Ed. da UNESP, 1999. p.11-15.

Professores: imagens do futuro presente. Lisboa: Educa, 2009.

MELLO, G. N. Magistério de $\mathbf{1}^{\mathbf{0}}$ grau: da competência técnica ao compromisso político. 4. ed. São Paulo: Cortez, 1984.

PEREIRA, L. A escola numa área metropolitana: crise e racionalização de uma empresa pública de serviços. São Paulo: Livraria Pioneira/Edusp, 1967.

PIMENTA, S. G. (Org.). Pedagogia, ciência da educação? 5. ed. São Paulo: Cortez, 1996.

RIOS, T. A. Compreender e ensinar: por uma docência da melhor qualidade. 6. ed. São Paulo: Cortez, 2006.

SANTOMÉ, J. T. Profesoras y profesores en el ojo del huracán. Foro de Educación, [S.1.], n.7-8, p.81-102, mai., 2006.

SAVIANI, D. História da história da educação no Brasil: um balanço prévio e necessário. Eccos - Revista Científica, São Paulo, v.10, n. Especial, p.147-167, 2008.

Pedagogia histórico-crítica: primeiras aproximações. 11. ed. Campinas:

Autores Associados, 2011.

TARDIF, M. Saberes docentes e formação profissional. 10. ed. Petrópolis: Vozes, 2010

VIDAL, D. G. Escola nova e processo educativo. In: LOPES, M.; FARIA FILHO, L.; VEIGA, C. (Org.). 500 anos de educação no Brasil. 4. ed. Belo Horizonte: Autêntica, 2010. p.497-517. 